\title{
Exploring the relationships between sexual violence, mental health and perpetrator identity: a cross-sectional Australian primary care study
}

\author{
Laura Tarzia ${ }^{1,2^{*}}$ D, Sharmala Thuraisingam ${ }^{1}$, Kitty Novy ${ }^{1}$, Jodie Valpied ${ }^{1}$, Rebecca Quake ${ }^{1}$ and Kelsey Hegarty ${ }^{1,2}$
}

\begin{abstract}
Background: Research supports the association between adult sexual violence (SV) and poor mental health. However, most studies focus on rape and physical sexual assault. Little is known about how more subtle forms of SV affect women's well-being. Furthermore, evidence for the impact of the perpetrator's identity is mixed. There is also little data from clinical populations to help health practitioners identify SV. This paper addresses these gaps by exploring the associations between different types of adult SV, perpetrator identity, and women's mental health in the Australian primary care setting.
\end{abstract}

Methods: We conducted a descriptive, cross-sectional study in general practice clinics. Adult women completed an anonymous survey while waiting for the doctor. Measures included PHQ-9 (depression), GAD-7 (anxiety) and PCL-C (post-traumatic stress disorder). SV was measured using items from the National Intimate Partner and Sexual Violence Survey and categorised into three groups (rape/sexual assault; coercive behaviours and/or reproductive control; and unwanted sexual contact).

Results: We found significant associations between rape/sexual assault and poor mental health, and between coercion and/or reproductive control and higher PTSD and anxiety scores, compared to women with no SV experiences. SV perpetrated by an intimate partner was associated with significantly higher mean PTSD scores than SV perpetrated by a stranger, and significantly higher depression scores than SV perpetrated by another known person.

Conclusion: Findings suggest that associations between SV and mental health are mediated by type of SV and perpetrator identity. Health practitioners should enquire about different types of SV beyond stranger rape as a cause of poor mental health, and about perpetrator identity to inform them about the likelihood of ongoing symptoms.

Keywords: Sexual violence, Mental health, Domestic violence/intimate partner violence, Sexual health, Women's health, Primary care

\footnotetext{
* Correspondence: laura.tarzia@unimelb.edu.au

${ }^{1}$ Department of General Practice, The University of Melbourne, 200 Berkeley

Street, Carlton, Victoria 3053, Australia

${ }^{2}$ Centre for Family Violence Prevention, The Royal Women's Hospital,

Parkville, Australia
}

(c) The Author(s). 2018 Open Access This article is distributed under the terms of the Creative Commons Attribution 4.0 International License (http://creativecommons.org/licenses/by/4.0/), which permits unrestricted use, distribution, and reproduction in any medium, provided you give appropriate credit to the original author(s) and the source, provide a link to the Creative Commons license, and indicate if changes were made. The Creative Commons Public Domain Dedication waiver (http://creativecommons.org/publicdomain/zero/1.0/) applies to the data made available in this article, unless otherwise stated. 


\section{Background}

Sexual violence against women (SV) is globally prevalent [1]. In Australia, approximately one in five women have experienced some form of SV since the age of 15 years [2]. Research consistently shows strong associations between adult SV victimisation and poor mental health [35], including anxiety, depression, and post-traumatic stress disorder (PTSD) [5]. However, there is inconsistency around what behaviours are included in the definition of 'sexual violence' [6]. The majority of SV literature focuses only on rape or physically violent sexual assault [7], yet SV also encompasses other behaviours such as coercion, reproductive control, unwanted sexual contact, and forced consumption of pornography [4]. With the exception of a few studies examining the mental health impacts of coercion as an aspect of intimate partner violence $[8,9]$, and one study from the Cote d'Ivoire on reproductive control [10], little is known about the health effects of these more subtle types of SV, despite their prevalence [11].

In an earlier study [6] we found that poor mental health in women attending Australian general practices was associated with SV, even when a broader definition was used. Women most commonly reported experiencing public harassment or flashing, unwanted groping, and being coerced into having sex. Despite the more subtle nature of these incidents compared to rape or violent sexual assault, women who had experienced SV in our sample were significantly more likely than those who had not to experience higher levels of anxiety and depression, although the association with depression disappeared after controlling for childhood sexual abuse. In the present study, we sought to unpack this finding further by exploring the relationship between poor mental health and specific types of SV.

Another poorly understood relationship is that between the identity of a perpetrator of SV and women's mental health. Studies consistently suggest that women are most likely to be sexually assaulted by a known perpetrator in their own home [12], yet community understandings of sexual violence typically focus on stranger rapes in dark alleyways. This is highly problematic, since compared to SV perpetrated by a stranger, SV at the hands of an intimate partner is associated with a higher risk of death or serious injury [13], exposure to multiple and repeated attacks [14], greater risk of sexually transmitted infection [15] and increased feelings of shame [16], all of which are likely to contribute to poor mental health outcomes. Despite this, findings around mental health and perpetrator identity have been mixed [1720]. For instance, Ullman et al. [19] found no significant differences in mental health outcomes between women raped by a stranger and those raped by an intimate partner. On the other hand, Abrahams et al. [17] found higher rates of depression in women raped by a known perpetrator rather than a stranger, although they did not distinguish between an intimate partner and another known person. Several other studies also found worse mental health outcomes associated with SV perpetrated by a partner, including PTSD, stress and dissociation [18], and hyperarousal [20]. The majority of these studies, however, focus on rape or violent sexual assault, and several include only women who had already disclosed, or who were seeking help for SV.

As well as a paucity of knowledge around the circumstances of SV experiences and how these impact on women's mental health, there is a lack of SV data from the primary care setting $[6,21,22]$. This is problematic given that the World Health Organization has recommended primary care as a key part of an effective early intervention and response [1]. The findings from our previous study suggest that almost half of women presenting to general practice clinics have experienced some form of SV [6], yet, health practitioners have little data from their own clinical population to guide practice.

The current paper aims to address these key gaps in the literature by reporting data from a cross-sectional study conducted in Australian general practice clinics. Our objectives are threefold: to explore the relationships between different types of sexual violence and mental health outcomes; to understand the relationship between perpetrator identity and mental health outcomes; and to provide data from a primary care sample to help guide practice. We argue that due to the complex relationship between women's mental health and SV victimisation, general practitioners (GPs) and other health professionals ought to consider a range of circumstances and situations beyond those of stranger rape when seeing female patients with mental health symptoms.

\section{Methods}

The present study built on previous work exploring the associations between women's mental health and SV described elsewhere [6]. We used a short (10-15 min) anonymous survey with women aged over 18 years delivered via iPad or on paper in the waiting room of participating GP clinics.

\section{Practice recruitment}

Information packs were posted to 101 private GP clinics in Victoria, Australia who had participated in a previous study on intimate partner violence [23]. A research assistant then telephoned the clinics a week later to follow up. The lead researcher attended interested clinics in person to speak with staff about the study. It was not a requirement that all doctors at a clinic agree participate in order for the clinic to be eligible. 


\section{Participants}

Eligible participants were adult women (>18) waiting to see a participating doctor, who were able to provide informed consent, and had sufficient English comprehension to complete a survey. We needed a sample size of 336 women to have sufficient power to detect one third of a standard deviation in mental health scores between those who had experienced SV and those who had not. Based on our previous study [6], we assumed similar proportions in each group.

\section{Measures}

SV experiences were determined using questions about 'Sexual Violence Victimisation' and 'Control of Reproductive and Sexual Health' taken from the US National Intimate partner and Sexual Violence Survey [11]. The items cover a broad range of behaviours including reproductive coercion, sex under the influence of alcohol or substances, rape and sexual assault, and unwanted kissing or touching. The identity of the perpetrator was asked using a single item developed for this study: 'What was the relationship of the perpetrator to you?'. The answer options were: stranger, boy/girlfriend, a date, a partner living with you now, a partner you were living with at the time (now ex-partner), an ex-partner that you were not living with at the time, a family member, a friend, any other acquaintance. Severity of current depressive symptoms was measured using the PHQ-9 [24], a well-validated tool which has shown very good psychometric properties in primary care settings [24]. Respondents were asked to indicate on a 4-point scale how often they had experienced each of the 9 items in the previous 2 weeks. Scores range from 0 to 27, with a range of 5 to 9 suggesting mild depression, 10 to 14 moderate depression, 15 to 19 moderately severe depression and 20-27 severe depression. Anxiety severity was measured using the generalised anxiety scale (GAD-7) [25], a well-validated and widely-used tool. The GAD-7 has shown excellent psychometric properties in prior research [26]. Respondents were asked to indicate how often they had experienced each of the 7 items in the last 4 weeks: $0=$ Not at all; $1=$ Several days; 2 = More than half the days. Scores could therefore range from 0 to 14 . Scores of 8 or above suggest possible presence of an anxiety disorder, when using the GAD-7 diagnostic algorithm for anxiety disorder, and scores of 5 or above suggest at least a mild level of anxiety. PTSD was measured using the PCL-C (civilian version) [27], a self-report tool with excellent test-retest reliability and high internal consistency. Scores for this measure range from 17 to 85 . Although the PCL-C is not strictly a diagnostic tool, studies have suggested that a score of 30 is a good predictor of PTSD diagnosis in a primary care sample [28], and could therefore be considered 'clinically meaningful'.

\section{Data collection}

Data were collected between March and August 2016. Research assistants were placed in the clinic waiting rooms. All patients were informed that a research project was in progress. Female patients arriving for their appointment were asked by the practice manager or receptionist whether they would mind being approached whilst waiting for the doctor. If the woman declined, this was recorded along with her date of birth and postcode (with permission and for comparison purposes only). The research assistants were then notified so that they did not disturb the patient. Practice managers also alerted the researchers to any patients who would not be able to consent due to ill health/disability or lack of English comprehension. For safety reasons, any female patient closely attended by a male partner was not approached. Eligible female patients who agreed to be approached were provided with an information sheet outlining the study. The research assistants answered any questions or concerns in person. Women were then given an iPad or paper survey to complete. Written consent via a tick box was built into the survey on the initial screen of the iPad or first page of the paper version.

Survey responses collected on the iPad were saved to the Cloud as soon as the participant submitted the survey. Data collected using paper surveys were manually entered by a member of the research team. Ten percent of the paper survey data was cross-checked by a second researcher.

A number of strategies were put into place to maximise the safety and well-being of participants. These included: providing all women with resource cards on completion of their survey; ensuring that doctors were provided with information on responding to disclosures of SV and child abuse; ensuring that all team members were trained to respond sensitively to participant distress; and providing private spaces in which to speak with women if needed.

\section{Data analysis}

STATA version 13.1 [29] was used for all analyses. Descriptive statistics were used to summarise participant demographics. SV items were categorised into three groups for analysis: 1 . rape or sexual assault; 2 . coercive behaviours and/or reproductive control without rape or sexual assault; 3. unwanted sexual contact only (see Table 1). Coercive behaviours and reproductive control were combined due to the similarities between the constructs. Perpetrator identities were collapsed into three categories: intimate partner, family member or other known person, and stranger. Linear mixed-effects models using restricted maximum likelihood estimation and random intercepts at the clinic level were used to estimate the mean difference in mental health score 
Table 1 Sexual violence items

\begin{tabular}{|c|c|}
\hline Item & Category \\
\hline \multicolumn{2}{|l|}{ Has anyone ever: } \\
\hline exposed their sexual body parts to you, flashed you, or masturbated in front of you? & \multirow[t]{6}{*}{ Unwanted sexual contact } \\
\hline harassed you while you were in a public place in a way that made you feel unsafe? & \\
\hline \multirow{4}{*}{$\begin{array}{l}\text { fondled or grabbed your sexual body parts? } \\
\text { kissed you in a sexual way? Remember, we are only asking about things that you didn't want to happen. }\end{array}$} & \\
\hline & \\
\hline & \\
\hline & \\
\hline \multicolumn{2}{|l|}{ When drunk, high, drugged or passed out and unable to consent, has anyone ever: } \\
\hline had vaginal sex with you? & \multirow[t]{4}{*}{ Rape/sexual assault } \\
\hline made you perform oral sex? & \\
\hline forced you to receive anal sex? & \\
\hline made you receive oral sex? & \\
\hline \multicolumn{2}{|l|}{ Has anyone ever used physical force or threats of physical harm to make you: } \\
\hline have vaginal sex with them? & \multirow[t]{6}{*}{ Rape/sexual assault } \\
\hline try to make you have vaginal, oral, or anal sex with you, but sex did not happen? & \\
\hline perform oral sex? & \\
\hline let them put their fingers or an object in your vagina or anus? & \\
\hline receive oral sex? & \\
\hline receive anal sex? & \\
\hline \multicolumn{2}{|l|}{ Have you ever had vaginal, oral or anal sex with someone after they pressured you by: } \\
\hline wearing you down by repeatedly asking for sex, or showing they were unhappy? & \multirow{3}{*}{$\begin{array}{l}\text { Coercive behaviours and/ } \\
\text { or reproductive control }\end{array}$} \\
\hline $\begin{array}{l}\text { doing things like telling you lies, making promises about the future they knew were untrue, threatening } \\
\text { to end your relationship, or threatening to spread rumours about you? }\end{array}$ & \\
\hline using their authority over you, for example, your boss or your teacher? & \\
\hline \multicolumn{2}{|l|}{ Have any of your romantic or sexual partners ever: } \\
\hline refused to use a condom when you wanted to use one? & \multirow{2}{*}{$\begin{array}{l}\text { Coercive behaviours and/ } \\
\text { or reproductive control }\end{array}$} \\
\hline $\begin{array}{l}\text { tried to get you pregnant when you did not want to become pregnant; or tried to stop you from using } \\
\text { birth control? }\end{array}$ & \\
\hline
\end{tabular}

between those who had experienced a form of SV and those who had not. Outcome measures were adjusted by clinic (cluster) and experience of childhood sexual abuse, given that both these variables could potentially influence both adult SV victimisation [30,31] and mental health [32-34]. Any participant characteristics that differed between those who experienced sexual violence and those who did not (see Table 2) were treated as potential confounders. These variables were tested in separate univariate models with the outcome variable, form of sexual violence and perpetrator identity. Only those variables found to be associated with both the outcome and independent variable were included as confounders in the adjusted model. Transformations for skewed continuous measures were considered. The distributions of residuals for each outcome were used to check the goodness of fit of the models and the influence of potential outliers on the regression models assessed. Under the linear mixed-effects regression model, missing data were assumed to be missing at random. Intra-clinic correlations for mental health outcomes were calculated using one-way analysis of variance.

Sensitivity analyses using pattern-mixture models were carried out to test the robustness of the missing at random assumption. For data that is missing at random, the difference between the mean of the missing data and the mean of the observed data $\delta$, is zero. The sensitivity analysis carried out in this study considers various plausible values for $\delta$ other than zero to simulate scenarios in which the missing data may not be missing at random. Positive values of $\delta$ indicate that participants with missing data have on average higher outcome scores than observed participants. Negative values of $\delta$ indicate that participants with missing data have on average lower outcome scores. In the sensitivity analyses, the regression analyses take into account the plausible values of $\delta$. These regression results 
Table 2 Demographics by experience of sexual violence $(N=325)$

\begin{tabular}{|c|c|c|c|c|}
\hline & \multicolumn{2}{|c|}{ Sexual violence $(N=126)$} & \multicolumn{2}{|c|}{ No sexual violence $(N=179)$} \\
\hline & & Missing & & Missing \\
\hline & n (\%) & n (\%) & n (\%) & n (\%) \\
\hline $\mathrm{Age}^{\mathrm{a}}$ & $50.5(17.1)$ & - & $57.8(18.8)$ & $1(0.6)$ \\
\hline Born in Australia & 99 (78.6) & - & $139(78.5)$ & $2(1.1)$ \\
\hline Aboriginal/Torres Strait Islander & $1(0.8)$ & $2(1.6)$ & - & $3(1.7)$ \\
\hline Completed high school & $99(82.5)$ & $6(4.8)$ & $115(65.0)$ & $2(1.1)$ \\
\hline Employed & $75(61.5)$ & $4(3.2)$ & $88(49.7)$ & $2(1.1)$ \\
\hline Married/defacto & $46(36.5)$ & - & $65(38.2)$ & $9(5.0)$ \\
\hline Lives alone & $18(14.3)$ & - & $40(23.5)$ & $9(5.0)$ \\
\hline
\end{tabular}

- represents $0(0 \%)$

$20(6.2 \%)$ with missing responses for sexual violence

${ }^{a}$ mean (standard deviation)

were compared with those from the main analysis to determine whether study conclusions changed if the missing data was not missing at random.

\section{Results}

Seven Victorian GP clinics were recruited, however, two dropped out due to lack of interest from doctors and one due to logistical issues. Four practices remained; two located in metropolitan Melbourne, one in an outer north-east suburb, and one in a coastal town in the Greater Geelong area. Thirty-two doctors were available across these clinics; 14 agreed to take part in the study. A total of 684/785 (87\%) women were approached and asked to participate (see Fig. 1). Overall, 325/428 (76\%) eligible women completed the survey, with between 7 and 125 women from each clinic (mean number of eligible participants per clinic $=81.3, \mathrm{SD}=53.5$; intraclass correlations for PTSD $=0.01$; depression $=0.009$; and anxiety $=0.01$ ). Reasons for non-participation included: the woman being too unwell; needing to attend to children; discomfort with the topic, or having insufficient time to complete the survey.

Table 2 shows the demographics of the sample by experiences of SV. Twenty women did not provide data for the sexual violence items, leaving a total of 305 women included in our analyses. The majority of women were born in Australia, had at least completed high school and were employed.

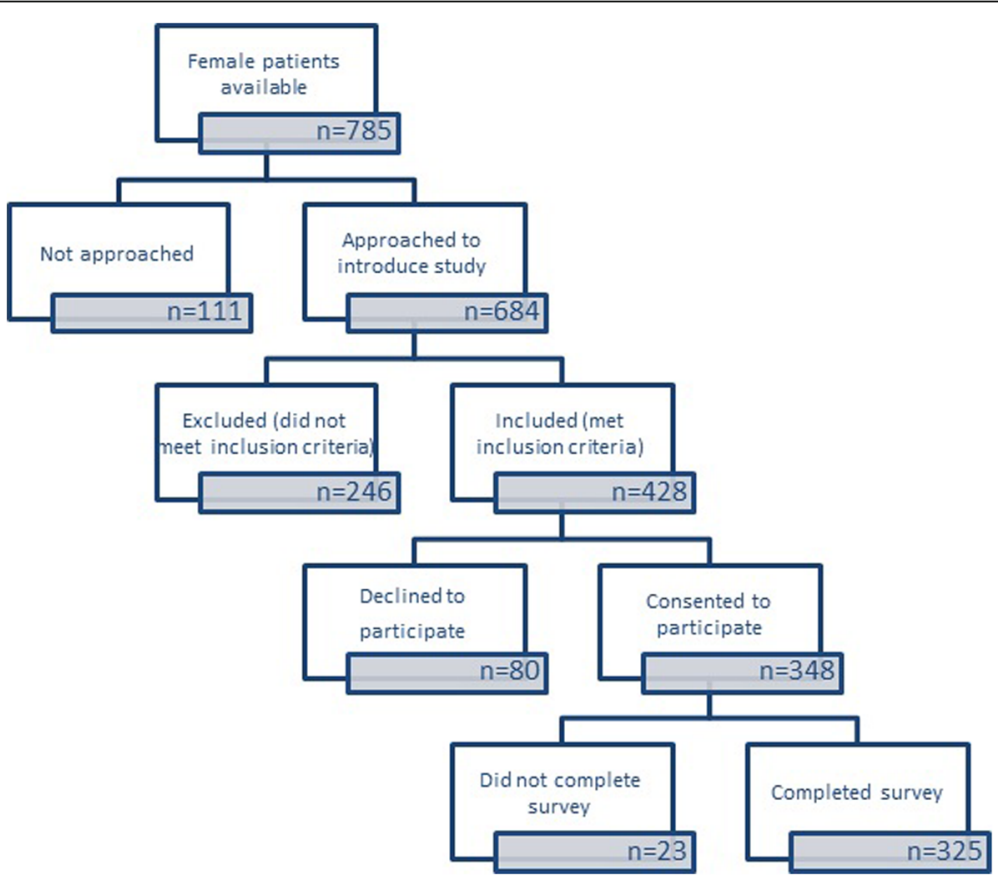

Fig. 1 Recruitment of sample 
Approximately $41 \%(n=126 / 305)$ of participants had experienced some form of SV since the age of 15 years, and $11 \%(n=34 / 305)$ had experienced it in the past 12 months. Sixteen percent $(n=48 / 305)$ had ever experienced rape or sexual assault. Overall, 17.5\% $(n=53 / 305)$ had ever been coerced into having sex or experienced reproductive control. Seven percent $(n=22 / 305)$ had experienced coercion and/or reproductive control without also having experienced rape or sexual assault. Eighteen percent (56/305) of women had experienced only unwanted sexual contact such as groping, harassment, flashing or touching.

Type of sexual violence experiences and mental health All outcomes, PCL-C, PHQ-9 and GAD-7, demonstrated good internal consistency and reliability (Cronbach's alpha $0.94,0.88$ and 0.76 respectively). There was a strong relationship between women's experiences of rape or sexual assault and poor mental health (see Table 3). Women who had been raped or sexually assaulted had on average significantly higher PTSD scores (mean difference $=10.5,95 \% \mathrm{CI}=6.8$ to 14.2 ) than women who had not experienced SV. These women also experienced significantly higher levels of anxiety (mean difference $=$ 2.3, $95 \% \mathrm{CI}=1.1$ to 3.5 ) and depressive symptoms (mean difference $=2.7,95 \% \mathrm{CI}=0.9$ to 4.4 ) compared to women with no SV experiences.
For women who had experienced coercive behaviour and/or reproductive control without rape or sexual assault, mean PTSD scores and mean anxiety scores were significantly higher compared to women who had not experienced SV $(\mathrm{PTSD}$ mean difference $=8.8,95 \% \mathrm{CI}=$ 3.9 to 13.7 ; anxiety mean difference $=2.7,95 \% \mathrm{CI}=1.2$ to 4.2). There was no statistical difference in mental health scores between those who experienced unwanted sexual contact alone and those who had not experienced sexual violence.

\section{Relationship between perpetrator identity and mental health}

Seventy-eight of the 126 women who had experienced SV responded to the perpetrator identity question. For those who responded to this item, SV perpetrated by an intimate partner (see Table 4) was associated with significantly higher mean PTSD scores than SV perpetrated by a stranger (mean difference $=8.0,95 \% \mathrm{CI}=0.8$ to 15.2). Intimate partner sexual violence was also associated with significantly higher mean depression scores than women assaulted by another known person (mean difference $=2.8,95 \% \mathrm{CI}=0.2$ to 5.4 ). There was little difference in anxiety scores between perpetrator types. Despite approximately $37 \%$ missing data for perpetrator type, sensitivity analyses testing the robustness of the missing at random data assumption revealed no change in conclusions (see Additional file 1).

Table 3 Mental health outcomes by type of sexual violence $(N=325)$

\begin{tabular}{|c|c|c|c|c|c|c|c|}
\hline \multirow{2}{*}{$\begin{array}{l}\text { Mental health } \\
\text { outcomes }\end{array}$} & \multirow{2}{*}{ Type of sexual violence } & \multirow[t]{2}{*}{$n$} & \multirow{2}{*}{$\begin{array}{l}\text { Mean score } \\
\text { (SD) }\end{array}$} & \multicolumn{2}{|l|}{ Unadjusted } & \multicolumn{2}{|l|}{ Adjusted $^{a}$} \\
\hline & & & & $\begin{array}{l}\text { Mean difference in mental } \\
\text { health outcome score }(95 \% \mathrm{Cl})\end{array}$ & $P$-value & $\begin{array}{l}\text { Mean difference in mental } \\
\text { health outcome score }(95 \% \mathrm{Cl})\end{array}$ & $P$-value \\
\hline \multirow[t]{4}{*}{ PTSD } & No experience of SV & 175 & $23.7(9.4)$ & - & $<0.001$ & - & $<0.001$ \\
\hline & Unwanted sexual contact (only) & 54 & $25.1(9.3)$ & $1.6(-1.6$ to 4.8$)$ & & $0.8(-2.5$ to 4.0$)$ & \\
\hline & $\begin{array}{l}\text { Coercive behaviour and/or } \\
\text { reproductive control }^{\mathrm{b}}\end{array}$ & 21 & 32.7 (11.9) & 10.1 (5.3 to 14.9$)$ & & 8.8 (3.9 to 13.7$)$ & \\
\hline & Rape/sexual assault (ever) & 48 & $36.8(14.4)$ & 13.2 (9.9 to 16.5$)$ & & 10.5 (6.8 to 14.2$)$ & \\
\hline \multirow[t]{4}{*}{ Depression } & No experience of SV & 176 & $4.4(5.0)$ & - & $<0.001$ & - & 0.016 \\
\hline & Unwanted sexual contact (only) & 54 & $4.8(5.0)$ & $0.4(-1.1$ to 1.9$)$ & & $0.1(-1.4$ to 1.6$)$ & \\
\hline & $\begin{array}{l}\text { Coercive behaviour and/or } \\
\text { reproductive } \text { control }^{\mathrm{b}}\end{array}$ & 22 & $6.2(4.4)$ & $2.0(-0.2$ to 4.2$)$ & & $1.5(-0.8$ to 3.7$)$ & \\
\hline & Rape/sexual assault (ever) & 48 & $8.3(5.1)$ & 3.9 (2.3 to 5.4$)$ & & 2.7 (0.9 to 4.4) & \\
\hline \multirow[t]{4}{*}{ Anxiety } & No experience of SV & 176 & $2.4(3.3)$ & - & $<0.001$ & - & $<0.001$ \\
\hline & Unwanted sexual contact (only) & 53 & $3.4(3.4)$ & $0.9(-0.1$ to 1.9$)$ & & $0.8(-0.3$ to 1.8$)$ & \\
\hline & $\begin{array}{l}\text { Coercive behaviour and/or } \\
\text { reproductive control }^{b}\end{array}$ & 21 & $5.3(3.3)$ & $3.0(1.5$ to 4.5$)$ & & 2.7 (1.2 to 4.2$)$ & \\
\hline & Rape/sexual assault (ever) & 46 & $5.8(3.7)$ & 3.3 (2.2 to 4.4$)$ & & 2.3 (1.1 to 3.5$)$ & \\
\hline
\end{tabular}

20 (6.2\%) participants had missing data for sexual violence

"No experience of SV" was used as the base level of the categorical exposure variable

${ }^{a}$ All models adjusted for clinic and experience of child abuse. PTSD and depression adjusted for age and employment status. Anxiety adjusted by age, employment status and whether participant had completed high school

bincludes those who have and have not experienced unwanted sexual contact 
Table 4 Mental health outcomes by perpetrator type $(N=126)$

\begin{tabular}{|c|c|c|c|c|c|c|c|}
\hline \multirow{2}{*}{$\begin{array}{l}\text { Mental health } \\
\text { outcomes }\end{array}$} & \multirow{2}{*}{$\begin{array}{l}\text { Perpetrator } \\
\text { type }\end{array}$} & \multirow[t]{2}{*}{ N } & \multirow{2}{*}{$\begin{array}{l}\text { Mean score } \\
\text { (SD) }\end{array}$} & \multicolumn{2}{|l|}{ Unadjusted } & \multicolumn{2}{|l|}{ Adjusted $^{a}$} \\
\hline & & & & $\begin{array}{l}\text { Mean difference in mental } \\
\text { health outcome score }(95 \% \mathrm{Cl})\end{array}$ & $P$-value & $\begin{array}{l}\text { Mean difference in mental } \\
\text { health outcome score }(95 \% \mathrm{Cl})\end{array}$ & $P$-value \\
\hline \multirow[t]{3}{*}{ PTSD } & Intimate partner & 30 & $36.8(12.2)$ & - & 0.098 & - & 0.086 \\
\hline & Stranger & 21 & $28.1(11.5)$ & $-7.9(-15.1$ to -0.7$)$ & & $-8.0(-15.2$ to -0.8$)$ & \\
\hline & Known person & 26 & $33.7(15.7)$ & $-2.9(-9.5$ to 3.7$)$ & & $-4.7(-11.7$ to 2.3$)$ & \\
\hline \multirow[t]{3}{*}{ Depression } & Intimate partner & 30 & $8.4(4.3)$ & - & 0.187 & - & 0.070 \\
\hline & Stranger & 21 & $5.9(5.4)$ & $-2.4(-5.2$ to 0.3$)$ & & $-2.4(-5.2$ to 0.3$)$ & \\
\hline & Known person & 26 & $6.7(5.6)$ & $-1.7(-4.3$ to 0.9$)$ & & $-2.8(-5.4$ to -0.2$)$ & \\
\hline \multirow[t]{3}{*}{ Anxiety } & Intimate partner & 28 & $5.6(4.0)$ & - & 0.501 & - & 0.587 \\
\hline & Stranger & 21 & $4.4(3.3)$ & $-1.2(-3.2$ to 0.8$)$ & & $-1.1(-3.2$ to 1.0$)$ & \\
\hline & Known person & 25 & $5.0(3.9)$ & $-0.6(-2.6$ to 1.4$)$ & & $-0.7(-2.9$ to 1.4$)$ & \\
\hline
\end{tabular}

48 (38\%) had missing responses to perpetrator

"Intimate partner" was used as the base level of the categorical exposure variable

${ }^{a}$ Model adjusted for clinic and experience of child abuse

\section{Discussion}

This cross-sectional study contributes to the knowledge base around women's experiences of adult SV and provides a more nuanced view of the associations between different types of SV and mental health. It also highlights the long-lasting impacts of SV, which are present even when past childhood sexual abuse is taken into account. The study also provides data from a clinical population; there is a lack of such information currently available $[21,22]$ to guide practice and shape an effective response from health professionals.

Consistent with the existing literature $[3,5]$, women who had ever experienced rape or sexual assault had higher mean levels of PTSD, anxiety and depression compared to women who had not experienced SV. Furthermore, the mean PTSD score for women who had been raped or sexually assaulted was above the suggested threshold of 30 for screening in a primary care setting [28], and mean depression and anxiety scores for these women fell within the symptomatic range (mild to moderate symptoms). Whilst this was an expected finding, it is nonetheless important information for GPs and other primary care providers; as it highlights that historical SV may still contribute to current mental health symptoms in their clinical population.

A key finding of this study was that women who had experienced coercive behaviours or reproductive control (without also having experienced rape or sexual assault) had significantly higher PTSD and anxiety scores than women who had experienced no SV. Mean anxiety scores for these women were very similar to those of women who had been raped or sexually assaulted, and again, the mean PTSD score was above the suggested diagnostic threshold for a primary care sample. Given the small numbers of women in each group, reaching statistical significance suggests that the relationship between these behaviours and poor mental health is strong. This is a critical finding that has important implications for practice. General practitioners and other health professionals responding to women should explore past experiences of coercion or reproductive control - in addition to rape and sexual assault - as a possible factor in otherwise unexplained mental health symptoms, particularly PTSD and anxiety.

Our study also sheds light on the relationship between women's mental health and the identity of the perpetrator. For those who responded to the perpetrator identify question, women assaulted by an intimate partner had significantly higher mean PTSD scores than women assaulted by a stranger and significantly higher mean depression scores than women assaulted by another known person such as a family member or friend. This supports the theory that SV perpetrated by an intimate partner has particularly serious impacts on women's mental health. This may be due to the increased level of fear for personal safety that many women experience when living with a perpetrator of violence [12], as well as the often ongoing and frequent nature of the abuse. It is also likely that the breach of trust and sense of humiliation women may experience $[35,36]$ after intimate partner sexual violence may contribute to poor mental health outcomes. Despite this, intimate partner sexual violence is often neglected or assumed to be less serious than assaults perpetrated by a stranger. Clinicians ought to enquire about the identity of the perpetrator in order to inform themselves about the likelihood of ongoing mental health problems in the future.

\section{Limitations of the study}

In the interests of keeping the survey brief, we were unable to capture data concerning the frequency of SV experiences, as well as other non-sexual traumas. Consequently, 
we have reported only associations rather than a causal relationship between SV and women's mental health, which could only be achieved through a longitudinal study. Furthermore, the response rate from recruiting general practice clinics, although consistent with other studies [23], was low, and this may have affected the generalisability of the findings. Lastly, our sample size was not powered for three categories of SV, which led to low numbers in some of the groups. Many women also chose to skip the perpetrator question in the survey. This may account for the lack of statistical significance on some of the outcome measures, although for those where significance was reached it suggests a strong relationship.

\section{Conclusions}

Our study found significant associations between women's experiences of being coerced into having sex or having their reproductive autonomy taken away, and poor mental health outcomes. While the associations between rape/physical sexual assault and poor mental health have previously been identified within the literature, little was known about how more subtle forms of SV might impact on women's well-being. The study also supports the theory that SV perpetrated by an intimate partner is particularly traumatic for women when compared to SV perpetrated by a stranger or another known person. These are important findings for health practitioners responding to women who present with otherwise unexplained mental health symptoms. This study represents an important first step in gaining a clearer picture of how SV impacts on women's mental health; more research with a larger population group is recommended in order to explore these relationships further.

\section{Additional file}

Additional file 1: Sensitivity analysis results. Results of sensitivity analyses using pattern-mixture models to test the robustness of the missing at random assumption. (DOCX $33 \mathrm{~kb})$

\section{Abbreviations}

GAD-7: Generalized Anxiety Disorder 7 item scale; GP: General practitioner (family doctor); PCL-C: Post-traumatic stress disorder checklist, civilian version; PHQ-9: Patient Health Questionnaire 9 item depression scale; PTSD: Posttraumatic stress disorder; SV: Sexual violence

\section{Acknowledgements}

Not applicable.

\section{Funding}

This study was funded by an Early Career Researcher Grant from The University of Melbourne. The funding body played no part in the study design, data collection, analysis, or in preparation of this manuscript.

\section{Availability of data and materials}

The datasets used and/or analysed during the current study are available from the corresponding author on reasonable request.

\section{Authors' contributions}

$L T, J V, K H$ and $R Q$ designed and conceptualised the study, each making substantial intellectual contributions. ST and JV developed and conducted statistical analyses. ST, JV, LT and KH interpreted the findings and their implications for practice. KN collected the data and managed study recruitment. LT and ST drafted the manuscript. All authors ( $L T, J V, K N, R Q, K H$ and ST) contributed to editing and critically revising the manuscript and all authors read and approved the final version. All authors agree to be accountable for all aspects of the work.

\section{Authors' information}

Not applicable

\section{Ethics approval and consent to participate}

Ethics approval was received for the study from the Human Research Ethics Committee at The University of Melbourne (\#1543699.1). Participants provided written consent to take part in the study via a tick box embedded in the first page of the survey.

\section{Consent for publication}

Not applicable.

\section{Competing interests}

The authors declare that they have no competing interests.

\section{Publisher's Note}

Springer Nature remains neutral with regard to jurisdictional claims in published maps and institutional affiliations.

Received: 23 May 2018 Accepted: 5 December 2018

Published online: 27 December 2018

\section{References}

1. World Health Organization. Responding to intimate partner violence and sexual violence against women: WHO clinical and policy guidelines. Geneva: WHO; 2013

2. Australian Bureau of Statistics. Personal Safety Survey. Canberra: Commonwealth Govt; 2012.

3. Pico-Alfonso MA, Garcia-Linares Ml, Celda-Navarro N, Blasco-Ros C, Echeburua E, Martinez M. The impact of physical, psychological, and sexual intimate male partner violence on women's mental health: depressive symptoms, posttraumatic stress disorder, state anxiety, and suicide. J Women's Health. 2006;15(5):599-611.

4. World Health Organization. Global and regional estimates of violence against women: prevalence and health effects of intimate partner violence and non-partner sexual violence. Geneva: WHO; 2013.

5. Chen L, Murad M, Paras M, Colbenson K, Sattler A, Goranson E, et al. Sexual abuse and lifetime diagnosis of psychiatric disorders: systematic review and meta-analysis. Proc Mayo Clin. 2010;85(7):618-29.

6. Tarzia L, Maxwell S, Valpied J, Novy K, Quake R, Hegarty K. Sexual violence associated with poor mental health in women attending Australian general practices. Aust N Z J Public Health. 2017;41(5):518-23.

7. Macdowall W, Gibson L, Tanton C, Mercer C, Lewis R, Clifton S, et al. Lifetime prevalence, associated factors, and circumstances of non-volitional sex in women and men in Britain: findings from the third National Survey of sexual attitudes and lifestyles (Natsal-3). Lancet. 2013;382(9907):1845-55

8. Mechanic M, Weaver T, Resick P. Mental health consequences of intimate partner abuse. Violence Against Women. 2008;14(6):634-54.

9. Varma D, Chandra P, Thomas T, Carey M. Intimate partner violence and sexual coercion among pregnant women in India: relationship with depression and post-traumatic stress disorder. J Affect Disord. 2007;102(1-3): 227-35

10. McCauley H, Falb KL, Streich-Tilles T, Kpebo D, Gupta J. Mental health impacts of reproductive coercion among women in cote d'Ivoire. Int J Gynaecol Obstet. 2014;127(1):55-9.

11. Black MC, Basile KC, Breiding MJ, Smith S, Walters ML, Merrick MT, et al. The national intimate partner and sexual violence survey: 2010 summary report. Atlanta: National Center for Injury Prevention and Control Centers for Disease Control and Prevention; 2010.

12. Cox P. Violence against women in Australia: Additional analysis of the Australian Bureau of Statistics' Personal Safety Survey 2012. ANROWS 
Horizons: 01/2015. Sydney: Australia's National Research Organisation for Women's Safety Limited (ANROWS); 2015.

13. Campbell J, Soeken K. Forced sex and intimate partner violence: effects on women's risk and women's health. Violence Against Women. 1999;5(9): 1017-35.

14. Mahoney P. High rape chronicity and low rates of help-seeking among wife rape survivors in a nonclinical sample: implications for research and practice. Violence Against Women. 1999;5(9):993-10106.

15. Allsworth J, Anand M, Redding C, Peipert J. Physical and sexual violence and incident sexually transmitted infections. J Women's Health. 2007;18(4): 529-34.

16. Wall L. Research report: the many facets of shame in intimate partner sexual violence. Melbourne: Australian Institute of Family Studies; 2012.

17. Abrahams N, Jewkes R, Mathews $S$. Depressive symptoms after a sexual assault among women: understanding victim-perpetrator relationships and the role of social perceptions. Afr J of Psychiatry. 2012;16:288-93.

18. Temple JR, Weston R, Rodriguez B, Marshall L. Differing effects of partner and nonpartner sexual assault on women's mental health. Violence Against Women. 2007;13(3):285-97.

19. Ullman S, Filipas H, Townsend S, Starzynski L. The role of victim-offender relationship in women's sexual assault experiences. J Interpers Violence. 2006;21(6):798-819.

20. Culbertson K, Dehle C. Impact of sexual assault as a function of perpetrator type. J Interpers Violence. 2001;16(10):992-1007.

21. Coid J, Petruckevitch A, Chung WS, Richardson J, Moorey S, Cotter S, et al. Sexual violence against adult women primary care attenders in East London. Br J Gen Pract. 2003;53(496):858-62.

22. Mazza D, Dennerstein L, Ryan V. Physical, sexual and emotional violence against women: a general practice-based prevalence study. Med J Aust. 1996;164(1):14-7.

23. Hegarty K, O'Doherty L, Taft A, Chondros P, Brown S, Valpied J, et al. Screening and counselling in the primary care setting for women who have experienced intimate partner violence (WEAVE): a cluster randomised controlled trial. Lancet. 2013;382(9888):249-58.

24. Kroenke K, Spitzer R, Williams J. The PHQ-9: validity of a brief depression severity measure. J Gen Intern Med. 2001;16(9):606-13.

25. Spitzer R, Kroenke K, Williams J. Validation and utility of a self-report version of PRIME-MD: the PHQ primary care study. Primary care evaluation of mental disorders. Patient health questionnaire. JAMA. 1999;282(18):1737-44.

26. Spitzer R, Kroenke K, Williams J, Lowe B. A brief measure for assessing generalized anxiety disorder: the GAD 7. Arch Intern Med. 2006;166(10): 1092-7.

27. Weathers FW, Huska JA, Keane TM. PCL-C for DSM-IV. In: Division NCfPSDBS, editor. . Boston; 1991.

28. U.S. Department of Veterans Affairs National Center for PTSD. Using the PTSD Checklist (PCL). USA; 2012.

29. StataCorp. Stata Statistical Software: Release 13. College Station: StataCorp LP; 2013.

30. Heise L. Violence against women: the hidden health burden. WHO Health Stat Q. 1993:46:78-85.

31. Coid J, Petruckevitch A, Feder G, Chung W, Richardson J, Moorey S. Relation between childhood sexual and physical abuse and risk of revictimisation in women: a cross-sectional survey. Lancet. 2001;358(9280):450-4.

32. Stordal E, Mykletun A, Dahl AA. The association between age and depression in the general population: a multivariate examination. Acta Psychiatr Scand. 2003;107(2):132-41.

33. Wise L, Zierler S, Krieger N, Harlow B. Adult onset of major depressive disorder in relation to early life violent victimisation: a case-control study. Lancet. 2001;358(9285):881-7.

34. Maniglio R. The impact of child sexual abuse on health: a systematic review of reviews. Clin Psychol Rev. 2009;29:647-57.

35. Easteal P, McOrmond-Plummer L. Real rape, real pain: help for women sexually assaulted by male partners. Melbourne: Hybrid Publishers; 2006.

36. Parkinson D. Raped by a partner: Nowhere to go, no-one to tell. Wangaratta: Women's Health Goulbourn North East; 2008.

\section{Ready to submit your research? Choose BMC and benefit from:}

- fast, convenient online submission

- thorough peer review by experienced researchers in your field

- rapid publication on acceptance

- support for research data, including large and complex data types

- gold Open Access which fosters wider collaboration and increased citations

- maximum visibility for your research: over $100 \mathrm{M}$ website views per year

At BMC, research is always in progress.

Learn more biomedcentral.com/submissions 